\title{
HABITABILIDAD Y AIRBNB: EL ALQUILER DE LA VIVIENDA EN EL DISTRITO CENTRO DE MADRID ${ }^{1}$
}

\author{
María Antonia Martínez-Caldentey* \\ Universitat de les Illes Balears \\ https://orcid.org/0000-0001-9865-1845 \\ Macià Blázquez-Salom \\ Universitat de les Illes Balears \\ https://orcid.org/0000-0002-5522-6539 \\ Ivan Murray \\ Universitat de les Illes Balears \\ https://orcid.org/0000-0001-6594-8423
}

\section{RESUMEN}

La irrupción del alquiler turístico, como el ofertado en Airbnb, ha provocado profundos cambios en torno a la vivienda y en los espacios urbanos. Así, Madrid se ha convertido de la mano del alquiler turístico, en una exitosa ciudad turística. En este artículo se analiza la proliferación del alquiler turístico en el distrito Centro de Madrid y su incidencia sobre el alquiler residencial. En este caso, como en otras ciudades europeas y norteamericanas, la explotación turística de las viviendas ha abierto la brecha de renta, mientras que el alquiler de las viviendas se ha disparado.

Palabras clave: vivienda; alquiler turístico; alquiler residencial; brecha de renta; Madrid.

\section{Habitability and Airbnb: Housing rentals in Madrid's Centro District}

\section{ABSTRACT}

The irruption of the tourist rental, like the one offered on Airbnb, has brought profound changes around housing and urban spaces. Madrid has become the hand of the tourist rental,

Fecha de recepción: 9 de mayo de 2019

Fecha de aceptación: 31 de octubre de 2019

* Departamento de Geografía. Universitat de les Illes Balears. Carretera de Valldemossa, Km.7,5, 07122 PALMA. Illes Balears (España). E-mail: maria.martinez.caldentey@gmail.com,mblazquez@uib.cat, ivan. murray@uib.cat

1 Contribuye al proyecto de investigación financiado por: FEDER, Ministerio de Ciencia, Innovación y Universidades y Agencia Estatal de Investigación, titulado “Overtourism in Spanish Coastal Destinations. Tourism Degrowth Strategies” (RTI2018-094844-B-C31). 
among other reasons, in a successful touristic city. This article analyses the proliferation of tourist rentals in the Central district of Madrid and its impact on residential rentals. In this case, as in other European and North American cities, the tourist exploitation of the houses has allowed to open the rent gap, while the rental price of the houses has skyrocketed.

Keywords: housing; tourist rental; residential rental; rent gap; Madrid.

\section{INTRODUCCIÓN}

Desde el estallido de la crisis, el turismo ha ido ganando más peso en la economía global. Particularmente, el mayor peso de la penetración ampliada del capital turístico se ha producido en aquellos Estados donde ya se practicaba un intenso monocultivo turístico, que además han resultado mucho más castigados por la crisis, como por ejemplo en los países meridionales de la Unión Europea: España, Italia y Grecia (Martínez-Caldentey y Murray, 2019). En este contexto, cabe situar la expansión de la frontera de la mercantilización turística en muchas ciudades europeas y norteamericanas. Después del estallido de la crisis, la economía política de las ciudades que se había centrado sobre todo en el nexo finanzas-vivienda, ha hecho un giro para resituarse sobre el nexo vivienda-turismo. En relación con lo anterior, cabe advertir que la explosión del conflicto urbano reciente se ha articulado, en buena medida, en torno a la mercantilización turística de la vivienda (Milano y Mansilla, 2018). Asimismo, debemos advertir el hecho que sobre esta corriente de intensificación turística se enmarcan las ciudades europeas y norteamericanas donde la frontera de mercantilización turística se ha desplazado, siendo enclaves geográficos donde el alojamiento turístico se ha asentado con fuerza (González-Pérez, 2019). Bajo este contexto, Madrid sirve de paradigma, pues ha ganado potencia también como espacio turístico bajo esta modalidad de alojamiento. No obstante, el desarrollo turístico en la capital es tremendamente desigual, pues es en el distrito Centro donde se encuentra la mayor concentración de este tipo de oferta (Benítez-Aurioles, 2017; García-Ayllon, 2018).

Si bien el alquiler turístico ha sido ampliamente tratado bajo el análisis académico, la interacción socioespacial acaecida de la diversificación mercantil de los usos de la vivienda en espacios muy turistizados, ha sido menos estudiada. Por ello, el objeto central de este artículo se ha construido en base al análisis de las tensiones socioeconómicas y espaciales del alquiler vacacional y el alquiler residencial en el distrito Centro de Madrid.

Desde la perspectiva del valor de uso de la vivienda, ambos fenómenos se encuentran en posiciones confrontadas, pues hipotéticamente la proliferación de uno se traduce en el menoscabo del otro. Además, esta dinámica conduce a una escalada de tensión entre visitantes y población residente, ante la creciente anteposición que plantea el turismo sobre el derecho a habitar la ciudad.

Partiendo de la hipótesis de que la proliferación del alquiler turístico se produce en detrimento del alquiler residencial, nos planteamos responder a las siguientes preguntas de investigación: 1) ¿Qué nivel socioeconómico e intensidad de Airbnb se da en los barrios de Centro, y cómo ello los hace más o menos resilientes de cara a Airbnb? 2) ¿cuál es 
la distribución espacial del solapamiento de las VUT sobre el alquiler residencial en los barrios de Centro? 3) ¿cuál es la brecha de renta entre el alquiler turístico y el residencial? 4) ¿puede influir el alquiler turístico sobre los precios del mercado inmobiliario y con ello, a la población residente?

Si bien en la actualidad la oferta del alquiler vacacional se encuentra presente en cada uno de los distritos de la ciudad de Madrid, es en su casco histórico donde se concentran más de la mitad del total de las plazas ofertadas mediante Airbnb. Sin embargo, la elevada pronunciación de esta actividad turística en el distrito Centro de Madrid, puede cambiar al verse regulada mediante políticas que han sido anunciadas recientemente por parte del Ayuntamiento de Madrid².

Tras la introducción, el cuerpo del presente artículo se ha articulado siguiendo los siguientes apartados. En primer lugar, se ha conformado la metodología, donde se explican las técnicas cuantitativas utilizadas para los análisis realizados. En segundo término, se encuentra el estado de la cuestión. En tercer lugar, se presentan los resultados obtenidos, los cuales se escinden según los apartados de: (1) caracterización de los barrios de Centro mediante Análisis Factorial; (2) el alquiler residencial en distrito Centro; (3) interacción espacial entre el alquiler residencial y el alquiler turístico, así como el cálculo de la brecha de renta entre ambos alquileres; (4) correlación entre los precios de las distintas modalidades del uso de la vivienda, como son: alquiler residencial, alquiler vacacional y compra-venta de viviendas de segunda mano en la ciudad de Madrid. Finalmente, el artículo se ultima mediante las conclusiones, siendo el apartado donde se compilan las reflexiones extraídas del conjunto analítico realizado.

\section{METODOLOGÍA}

Las bases de este estudio se han fundamentado en los cálculos hechos a partir de un conjunto amplio de datos procedente de diversas fuentes tratadas con técnicas cuantitativas, ya sea desde la perspectiva estadística, como desde la del análisis espacial del alquiler de la vivienda.

Por un lado, se ha llevado a cabo un Análisis Factorial Multivariante (AF) para estudiar las características socioeconómicas de los barrios de Centro, así como el peso de Airbnb en cada uno de los barrios de este distrito. Los datos para el estudio de la situación socioeconómica se han extraído de las fuentes estadísticas oficiales del Ayuntamiento de Madrid y del Catastro. Mientras que los datos sobre el alquiler residencial provienen del Censo de 2011, así como de Idealista mediante una muestra tomada en el año 2018 a través de web scraping ${ }^{3}$. El web scraping es una técnica de extracción y compilación de datos alojados en una página web. Debido a la falta de información pública sobre el alquiler y la situación inmobiliaria actual, es necesario recurrir a este tipo de técnicas hacker, pues son las empresas privadas las que tienen el monopolio de esta información.

2 Aprobado el Plan Especial para la regulación de uso terciario en su clase de Hospedaje. Disponible en: https://diario.madrid.es/blog/notas-de-prensa/aprobada-definitivamente-la-regulacion-para-viviendas-de-usoturistico/

3 Datos extraídos de Idealista y compartidos en marzo de 2018 por H. Meleiro en https:/github.com/ meneos/TallerMontera34/tree/master/data. 
La oferta del alquiler vacacional se ha obtenido a través de la extracción de datos compilados por InsideAirbnb y DataHippo en Airbnb para 2018, con los cuales se ha construido una base datos propia mediante hojas de cálculo. De nuevo se ha recurrido a fuentes externas para la recolección de estos datos, porque la administración pública, que es la que debería tener control sobre la oferta turística que se produce en las ciudades, se encuentra totalmente desnuda, mientras que Airbnb es reticente a la transparencia.

El Análisis Factorial es un tipo de técnica que se utiliza para el estudio y la interpretación de las correlaciones encontradas en base a un conjunto de variables. Su objetivo es descubrir los posibles factores comunes a todas las variables que se estudian (Brunet et al., 2002). Entre las grandes ventajas que tiene el AF se encuentra el poder tratar un gran número de distintas variables, las cuales se traducen en una gran cantidad de información. Para el procedimiento general que sigue el análisis factorial, se distinguen los siguientes pasos:

- Análisis de componentes principales y prueba de esfericidad de Bartlett. La prueba de Bartlett comprueba la hipótesis de que si la matriz de correlaciones tiene un nivel de significación menor a 0,05 se puede aplicar el análisis factorial (Bosque y Moreno, 1994).

- Rotación de factores mediante el método Varimax. Siendo un tipo de rotación ortogonal que consiste en maximizar la varianza de los factores.

- Cálculo de las puntuaciones factoriales. La etapa final de los cálculos del AF muestra las puntuaciones de cada una de las unidades espaciales para cada uno de los factores extraídos.

Asimismo, también se ha llevado a cabo un estudio de correlación $r$ de Pearson para el análisis de la relación dada entre los precios que toman las distintas mercantilizaciones de la vivienda en Madrid. El coeficiente de correlación $\mathrm{r}$ de Pearson es capaz de medir la magnitud y el signo de la relación entre dos o más variables cuantitativas (Rogerson, 2015). Este método da como resultado una matriz de correlaciones con la que se puede observar cómo de relacionadas están las variables, así como que tipo de información pueden aportar. La fuerza de la correlación entre las variables queda medida mediante el valor absoluto del coeficiente $\mathrm{r}$, de forma que cuanto más cerca esté de 0 , menor será la relación entre las variables, mientras que cuanto más cerca esté de 1, mayor será la relación entre ellas (Camacho, 2005). Asimismo, $r$ también indica el signo de la relación, pues si es positivo indica que, a mayor valor en una variable, mayor valor en la otra variable; mientras que si es negativo señala que, a mayor valor de una variable, menor valor en la otra variable (Camacho, 2005).

Todo lo descrito anteriormente se ha llevado a cabo mediante el uso del programa estadístico IBM SPSS. En cuanto a las funciones concretas utilizadas, éstas han sido: la correlación bivariada (correlación $\mathrm{r}$ de Pearson) y el análisis factorial (reducción de datos).

Por otro lado, se han analizado los patrones espaciales de la vivienda desde el estudio del peso que tiene el alquiler vacacional sobre el alquiler residencial en Centro a escala de sección censal. Ello se ha hecho a través de Sistemas de Información Geográfica y en particular, de ArcGIS. El resultado obtenido de ello ha sido una cartografía detallada sobre la confrontación entre estos dos tipos de comercialización, así como donde se concentran cada uno sobre las secciones censales del distrito Centro. 
Por último, se ha calculado la brecha de renta en base a la siguiente fórmula (Wachsmuth y Weisler, 2018).

$$
\text { Brecha de renta }=\frac{\text { Renta media Airbnb }}{\text { Renta media Airbnb }+ \text { Renta media residencial }}
$$

Este se basa en el cálculo de la proporción entre la media de la renta residencial y la renta media del alquiler vacacional, proporcionando así, la diferencia de renta entre ambos $\mathrm{y}$, por tanto, la ganancia extra que se consigue mediante un tipo de alquiler sobre el otro. El resultado de este indicador varía entre el valor 1 -una brecha totalmente abierta- y 0 -una brecha completamente cerrada-. Gracias a la brecha de renta se puede comprender el trasvase que se ha ido produciendo desde el alquiler de larga duración, hacia el vacacional o de corta duración. Siendo uno de los arietes que han hecho que el fenómeno propiciado por Airbnb haya tenido un éxito masivo en tantas ciudades del mundo.

Asimismo, cabe decir que el cálculo de la brecha de renta no es exacto ni directo, sino que solo aporta una aproximación de ésta, puesto que se basa en conceptos abstractos de difícil cuantificación (Wachsmuth y Weisler, 2018). Igualmente ocurre con el análisis del solapamiento y trasvase entre el alquiler turístico y el residencial, pues la gran falta de datos al respecto de la vivienda hace que a menudo tales investigaciones deban manejarse con menos luz de la que debieran. Otro tanto ocurre con los datos respecto al alquiler, ya sea de largo o corto plazo, pues si bien para el primero la información es antigua, para el segundo se carece de la totalidad del volumen de datos debido a la reticencia de Airbnb para hacerlos públicos. Sin embargo, se puede afirmar que, a pesar de las dificultades encontradas, sobre todo de cara al acceso de información necesaria para el estudio, es posible visualizar los efectos que produce el alquiler turístico sobre la vivienda, la socioeconomía, así como sobre el propio territorio donde se desarrolla este fenómeno.

\section{ESTADO DE LA CUESTIÓN. MERCANTILIZACIÓN DEL HÁBITAT, ECO- NOMÍA COLABORATIVA Y AIRBNB}

La mercantilización de la vivienda a través de su valor de cambio, dejando contradictoriamente su valor de uso relegado a un segundo plano, no deja de resultar disonante, pues la vivienda se constituye como un medio imprescindible para la vida de las personas (Harvey, 2014). De esta forma, la vivienda es apreciada como un medio con el cual extraer rédito económico, encadenando su valor de cambio a la especulación (Blanco et al., 2018).

Mediante la mercantilización turística masiva de los inmuebles se provoca la desnaturalización de los espacios urbanos al perder la calidad de hábitats. En este sentido, algunos autores han descrito la habitabilidad como el zumbido que se produce al vivir y habitar un espacio físico, el cual es modulado por el conjunto de actividades desarrolladas por las personas (Silver y Nichols, 2013). La oferta y la demanda turística generada en torno a los cascos históricos bascula entre el consumo de arte y cultura; el redescubrimiento de lo urbano y el creciente interés por la política urbana (Silver y Nichols, 2013; Mínguez et al., 2018). 
El asalto del turismo en los barrios no provoca solo la pérdida de habitabilidad mediante la acumulación por desposesión, siendo el resultado de la gentrificación, sino que también acrecienta la vulnerabilidad de la población residente. La vulnerabilidad, por su parte, no se encuentra repartida uniformemente a lo largo de la ciudad, pues es en los barrios populares donde el riesgo es mayor, como son los del sud de la ciudad de Madrid (Méndez y Prada-Trigo, 2014; Hernández-Aja, et al.,2015).

La especulación, alimentada por la ambición de maximizar el valor de cambio, ha sido el pasto de las crisis vividas, como la que estalló en 2008. La cual se convirtió en la flagrante demostración, de que las crisis capitalistas basadas en la especulación sobre el valor de cambio tienen sus repercusiones sobre el acceso de la población al valor de uso, como el de la vivienda (Harvey, 2014).

El año 2008 fue un año de crisis, y por tanto de destrucción creativa, mediante la cual el capitalismo volvió a mutar para subsistir, transformando a su paso el mercado global. Ejemplos de tales mutaciones y transformaciones, son las recientes plataformas digitales (Rivera et al., 2017). A partir de las cuales se produjo el auge de la llamada economía colaborativa, sirviéndole de combustible los efectos reproducidos por la recesión, como son: el desempleo, la precariedad laboral y la dificultad de obtener suficientes ingresos para vivir (Rivera et al., 2017).

Tales plataformas tecnológicas sirvieron asimismo como complemento de la industria turística, siendo ésta una de las respuestas dadas para combatir la recesión económica de 2008. De la mano del turismo se captaron nuevos nichos para la reproducción del capital (Cañada y Murray, 2019).

Airbnb, como ejemplo de plataforma digital de éxito, basa su actividad al insertar en el mercado prácticas -como rentar turísticamente una habitación del propio hogar- que no formaban parte de este en el pasado o lo hacían, pero bajo una forma anecdótica e informal. De forma que, en la actualidad, se mercadea masivamente y a escala global mediante un medio digital con recursos que se consideran ociosos o infrautilizados con el objetivo de rentabilizarlos (Rivera et al., 2017).

La explotación de la vivienda a través del alquiler turístico en las urbes tiende a alejarse de la economía colaborativa, contrariando el discurso formal de Airbnb, el cual se esgrime para convencernos de qué economía colaborativa y Airbnb son conceptos homólogos (Crommelin et al., 2018; Mínguez et al., 2018). Cuando el alquiler turístico se produce de forma masiva e intensa, beneficia principalmente a los grandes propietarios, mientras favorece el estrangulamiento de la oferta del alquiler residencial, con el consecuente encarecimiento de los arrendamientos (Horn y Merante, 2017; Yrigoy, 2017). Asimismo, la elevación de los alquileres de larga duración, se encuentran influidos, además de por el alquiler turístico, por otros factores, como son: la escasa presencia de vivienda pública de alquiler, el aumento de la población residencial flotante y la compra masiva mediante inversión extranjera, cuya intención es la especulación inmobiliaria (Blanco et al., 2018; Cócola, 2016).

Siguiendo a Cañada y Murray (2019), la saturación producida por el turismo urbano en muchas ciudades del Norte Global ha apuntalado la desazón sentida de cara a la turistificación del territorio, entendiendo la industria turística como una vía de acumulación 
del capital que no cumple con las expectativas inculcadas años atrás sobre la mejora del bienestar social.

La economía colaborativa desarrollada a modo de marketing por estas grandes empresas ha alumbrado la prosumición y al prosumidor (Gil, 2017; Rivera et al., 2017). La figura del prosumidor deviene como el ideal del neoliberalismo (Rivera et al., 2017), pues cada individuo se convierte a su vez en productor y consumidor, de forma que la prosumición ha desintegrado la frontera entre: las personas, la producción y el consumo (Gil, 2017). Así, el consumidor/turista se convierte en el productor mediante la explotación de la vivienda a través de Airbnb. Asimismo, y a través de la disolución entre productor/consumidor, también se confunden el valor de uso y de cambio. Porque si en un principio, un bien es llevado al mercado en forma de mercancía, cuando su tenedor deshecha el valor de uso del bien y quiere explotarlo mediante su valor de cambio (Harvey, 2014); con la prosumición, tal proceso se ve alterado.

Sin duda, el caos socioeconómico parece ser el gran acompañante de estas recientes, pero potentes plataformas tecnológicas, así como la forma de interactuar en el mercado capitalista como prosumidor. Aunque si bien es cierto, que muchas circunstancias han cambiado, la esencia es la misma, pues Airbnb se conforma bajo los términos del capitalismo neoliberal y su éxito se fragua en la obtención de la plusvalía que generan los trabajadores, o en este caso: prosumidores. Es importante destacar, que la figura del trabajador que exigen empresas como Airbnb, ahonda en un tipo de trabajo estrictamente flexible y precario (Cockayne, 2016). Porque bajo la figura del anfitrión que alquila su hogar o parte de este, se encuentra un trabajador con múltiples tareas, que no solo trabaja para sí mismo, sino para una empresa que se alimenta de su fuerza de trabajo sin haberlo contratado (Cockayne, 2016).

La producción urbana a través del sistema capitalista se tensiona así, bajo el peso de las contradicciones acarreadas por el devenir del sistema, el cual se construye en busca del crecimiento económico continuo. La transmutación del uso de la vivienda, de hábitat a "hospedería", no es más que el ensanchamiento de los límites del neoliberalismo sobre la morfología urbana, pues si bien el derecho a habitar está enajenado bajo la propiedad privada, la explotación masiva de la vivienda bajo la producción turística permite acelerar la concentración de capital a costa de la expulsión de la mayoría social. Bajo esta realidad se encuentran muchas ciudades europeas, y entre ellas, la ciudad de Madrid sirve de paradigma. El casco histórico madrileño se erige así, como el escenario donde se produce la confrontación entre la explotación capitalista de la vivienda y la necesidad de habitar la ciudad (Gil y Sequera, 2018; Mínguez et al., 2018).

De todo ello, cabe preguntarse: ¿existiría el volumen de alquiler turístico actual, sin la figura de especuladores inmobiliarios o bien de personas que el mercado laboral es incapaz de sostener al no proporcionarles estabilidad económica? En otras palabras, ¿sin la especulación por parte de unos pocos y la precariedad de otros muchos? Si la respuesta resulta negativa, será necesario realizar un planteamiento más profundo sobre el tipo de actividad que desarrollan este tipo de empresas, las cuales dan una vuelta de tuerca más a las exigencias del neoliberalismo para la subsistencia material de gran parte de la población. 


\section{CARACTERIZACIÓN DE LOS BARRIOS DE DISTRITO CENTRO}

La caracterización socioeconómica de los seis barrios de Centro se ha llevado a cabo en base a un análisis factorial multivariante realizado a través de un conjunto de nueve variables cuantitativas.

La escala espacial del estudio ha sido la de barrio, ya que la sección censal, que es la unidad territorial más detallada para caracterizar un territorio, apenas cuenta con información estadística actual con la que poder trabajar. Asimismo, cabe decir que, para la escala de barrio, la cantidad de información es más bien escasa, pero qué es por la que se ha optado, al permitir el análisis del distrito a través del conjunto de sus partes y no como un único cuerpo homogéneo, de forma que se puedan apreciar las diferencias entre los barrios, sobre todo la dicotomía norte-sur. Asimismo, el momento analizado ha sido el actual. Por ello, se ha escogido la información del propio año 2018 o 2017 siempre que se ha podido, y en su defecto la del 2016 o 2015, al ser los años más próximos a la actualidad en los que se disponía de tales datos.

La elección de las variables con las que se ha trabajado ha pretendido reflejar los rasgos socioeconómicos y educativos de los barrios, así como la influencia que en ellos tiene la vivienda y Airbnb. Las nueve variables analizadas han sido:

- Variable 1. Renta neta. Renta media por hogar en euros ${ }^{4}$. Año 2015.

- Variable 2. Hipoteca. Importe medio de hipoteca en euros ${ }^{5}$. Año 2016.

- Variable 3. Vivienda de segunda mano. Media del precio de compraventa de la

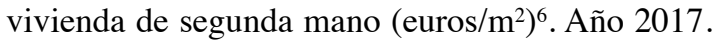

- Variable 4. Superficie de la vivienda. Superficie media de la vivienda en transacción $\left(\mathrm{m}^{2}\right)^{7}$. Año 2016.

- Variable 5. Educación secundaria y superior. Porcentaje de personas con educación secundaria y superior ${ }^{8}$. Año 2017.

- Variable 6. Desempleo. Porcentaje de personas desempleadas ${ }^{9}$. Año 2017.

- Variable 7. Cantidad de alquiler vacacional. Porcentaje de alquiler turístico ofertado en Airbnb sobre el total de inmuebles residenciales del catastro $2017^{10}$. Año 2018/2017.

- Variable 8. Capacidad de alojamiento. Capacidad total de alojamiento mediante alquiler turístico ofertado en Airbnb ${ }^{11}$. Año 2018.

\footnotetext{
4 Indicadores Urban Audit para áreas submunicipales (2015).

5 Ayuntamiento de Madrid. Banco de datos.

Ayuntamiento de Madrid. Banco de datos.

Ayuntamiento de Madrid. Banco de datos.

Indicadores Urban Audit para áreas submunicipales (2017).

9 Indicadores Urban Audit para áreas submunicipales (2017).

10 InsideAirbnb y Catastro 2017.

11 InsideAirbnb.
} 
- Variable 9. Precio del alquiler vacacional. Precio medio en euros por noche del alquiler turístico ofertado en Airbnb ${ }^{12}$. Año 2018.

El análisis factorial llevado a cabo a partir de las nueve variables descritas ha dado como resultado dos factores, tal y como se aprecia en el cuadro 1. Entre los componentes medidos, se ha obtenido un total de varianza explicada del $57,16 \%$ y del $79,12 \%$. De forma que el primer componente ya ha contenido más de la mitad de la información que albergaban las variables analizadas.

En cuanto a la viabilidad del Análisis Factorial, cabe decir que en el índice KaiserMeyer-Olkin se ha obtenido un valor de 0,803 mostrando una correlación notable entre las variables. Mientras que el valor de significancia de la esfericidad de Bartlett se ha encontrado por debajo del 0,05 , demostrando que es significativa la realización del AF.

\section{Cuadro 1}

MATRIZ DE COMPONENTES ROTADOS

\begin{tabular}{|c|c|c|}
\hline \multirow{2}{*}{ Matriz de componentes rotados } & \multicolumn{2}{|c|}{ Factores } \\
\cline { 2 - 3 } & $\mathbf{1}$ & $\mathbf{2}$ \\
\hline Variable 1. Renta neta media de los hogares & 0,93 & \\
\hline Variable 2. Hipoteca media & 0,91 & \\
\hline Variable 6. Desempleo & $-0,90$ & \\
\hline Variable 3. Precio vivienda de segunda mano & 0,82 & \\
\hline Variable 5. Estudios medios y superiores & 0,80 & \\
\hline Variable 4. Superficie media de la vivienda & 0,78 & \\
\hline Variable 9. Precio de Airbnb por noche & 0,77 & \\
\hline Variable 8. Capacidad de alojamiento mediante Airbnb & & 0,94 \\
\hline Variable 7. Airbnb sobre inmuebles residenciales & & 0,93 \\
\hline
\end{tabular}

La matriz rotada representada en el cuadro 1 expresa la misma información de la matriz de componentes, solo que redistribuye la varianza de los factores, haciendo que la matriz rotada resulte más fácil de comprender al presentar los coeficientes más próximos a cero o a uno, facilitando con ello el análisis (Bosque y Moreno, 1994). Asimismo, los factores obtenidos a partir del AF realizado, se han interpretado a partir de los valores más elevados obtenidos para cada una de las variables. Los factores extraídos, han sido:

Factor 1. Nivel socioeconómico. Este primer factor se encuentra relacionado de forma positiva con las variables de renta media por hogar, con el importe medio de

12 InsideAirbnb. 
la hipoteca, la superficie media de los inmuebles, el precio medio de la vivienda de segunda mano y de Airbnb, así como con el porcentaje de personas con estudios medios y superiores. De todo ello se extrae, que tales variables se encuentran ligadas a niveles socioeconómicos elevados, relacionándose a su vez con unas condiciones de vida que resultan ser más caras.

Por el otro el lado, el desempleo se correlaciona negativamente con el factor, es decir, que cuanto más elevado sea este, más bajo será el nivel económico de la sociedad en cuestión.

Factor 2. Intensidad de Airbnb. El segundo factor extraído se encuentra ligado positivamente con la cantidad de alojamiento vacacional y el porcentaje de Airbnb sobre el conjunto de las viviendas residenciales. Mediante este factor se ha medido la intensidad del arrendamiento vacacional ofertado en Airbnb en cada uno de los barrios del distrito Centro, pudiéndose entender como un proxy del nivel de turistización espacial.

\subsection{Cartografía y resultados del análisis factorial}

\subsubsection{Factor 1. Nivel socioeconómico}

El primer factor representado en la figura 1, es el que aglutina más variables explicadas, dibujando un distrito Centro dividido en tres zonas, a saber: un este de valores positivos, un centro y oeste de niveles medios y un sur de valores bajos.

Comenzando por el sur, se encuentra Embajadores con el nivel socioeconómico más bajo del distrito. Las razones de ello se encuentran principalmente en tener el desempleo más elevado de Centro, así como la renta media por hogar más baja del conjunto de los seis barrios. En cuanto a la vivienda, la media de precios y de hipotecas son las más económicas de Centro, aunque la superficie media de la vivienda es la menor del conjunto del distrito.

Siguiendo por los barrios de Sol, Palacio y Universidad, se encuentra el nivel socioeconómico medio. Los valores de estos tres barrios se caracterizan por encontrarse en la equidistancia entre Embajadores y Justicia. Las medias de la renta por hogar son medio-altas; el desempleo es medio-bajo, mientras que la educación media y superior es elevada. En cuanto a las características inmobiliarias, la media del importe de las hipotecas oscila entre los 190.000 y los 203.000 euros, -unos 60.000 euros más caras que en Embajadores- mientras que la superficie media de las viviendas está entre los 66 y 77 metros cuadrados, siendo en Universidad donde se encuentran las viviendas de menor superficie.

Por último, los barrios de Cortes y Justicia son los que se enmarcan bajo el nivel socioeconómico más elevado. En Cortes, se presenta una renta por hogar de 35.000 euros, mientras que en Justicia asciende hasta los 40.000 euros. Asimismo, el desempleo en estos barrios es el más bajo del distrito. Los porcentajes en la educación media y superior son muy elevados. Mientras que las viviendas son las que tienen la media más alta por superficie, pero también donde los precios de éstas y las hipotecas son más elevados. 


\section{Figura 1 \\ MAPA DEL NIVEL SOCIOECONÓMICO DE LOS BARRIOS DE CENTRO}

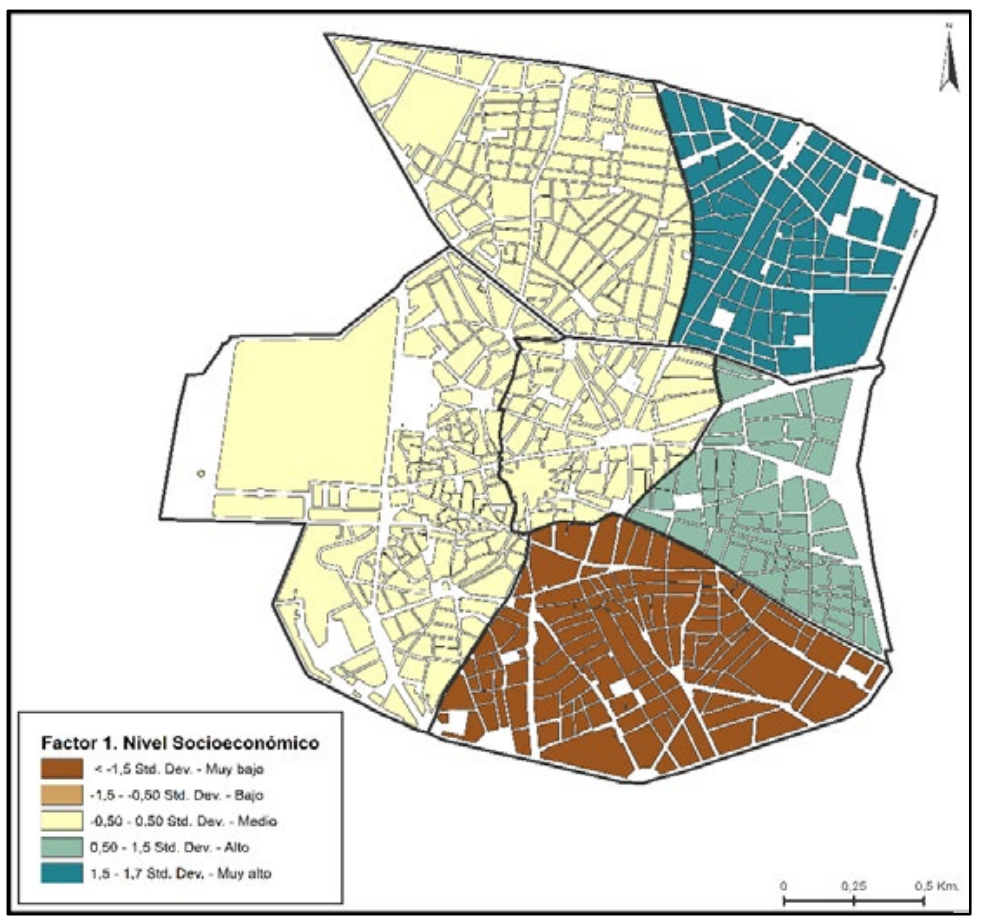

Fuente: Elaboración propia a partir del Ayuntamiento de Madrid y DataHippo.

\subsubsection{Factor 2. Intensidad de Airbnb}

El segundo factor analizado, expuesto en la figura 2, basa la categorización de los barrios en dos variables: la cantidad de alojamientos turísticos sobre el conjunto de los inmuebles residenciales y la capacidad de alojamiento.

Sol es el barrio que tiene el mayor peso de viviendas que operan mediante Airbnb sobre el conjunto de inmuebles residenciales, alcanzando el 37,34\% sobre el total. Así, Sol se convierte en el barrio con la mayor presión de alquiler turístico y el más turistizado de la ciudad de Madrid. Asimismo, Embajadores es el barrio de Centro con la mayor capacidad de alojamiento mediante alquiler de corta duración, aunque la proporción de estos respecto del total de inmuebles residenciales es algo inferior a Sol. Bajo una intensidad media, se encuentra el barrio de Universidad, siendo el segundo barrio de Centro con la mayor capacidad de alojamiento mediante alquiler turístico.

La categorización más baja de este factor, la tienen de mayor a menor: Palacio, Cortes y Justicia. En cuanto a la capacidad de alojamiento, Palacio se posiciona a la cabeza de los tres barrios, mientras que Cortes es el barrio con el porcentaje más elevado de vivien- 
das que operan como alojamientos turísticos mediante Airbnb de los tres, alcanzando el $18,20 \%$. Por su parte, Justicia es el barrio con los valores más moderadamente bajos de las variables medidas, si bien es cierto que los tres barrios con las intensidades más bajas de Centro se encuentran bajo un nivel muy similar.

Asimismo, y si bien en este apartado solamente se han representado los barrios de Centro, cabe decir que, si se comparan con el resto de los barrios de la ciudad de Madrid, la intensidad que se ejerce a través del alquiler turístico, sin duda es muy elevada en los seis barrios de distrito Centro, pues la presión de Airbnb que soportan los demás barrios de la ciudad de Madrid es bastante inferior. De forma que se demuestra lo fuertemente concentrado que está este tipo de alquiler en el casco histórico de la ciudad de Madrid, además de mostrar que es la zona de la ciudad más turistizada.

Figura 2

\section{MAPA DE LA INTENSIDAD DE AIRBNB EN LOS BARRIOS DE CENTRO}

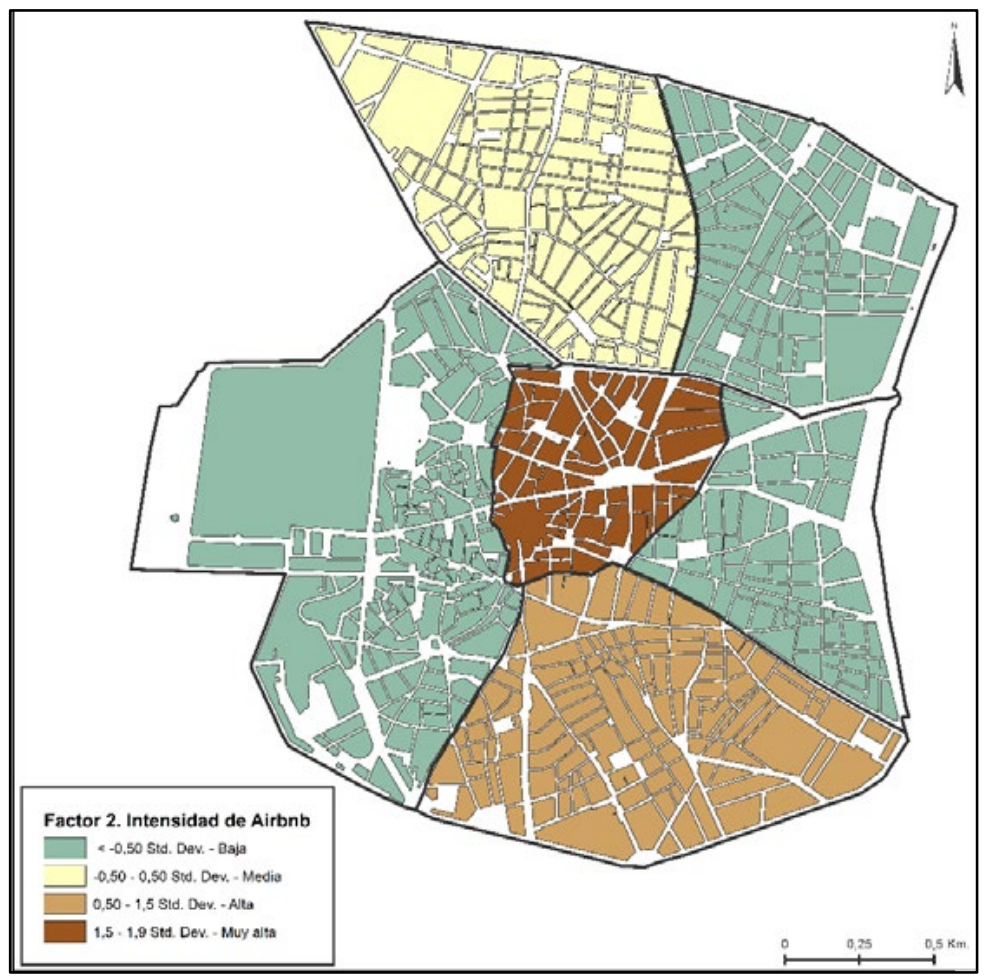

Fuente: Elaboración propia a partir del Ayuntamiento de Madrid y DataHippo.

Tal y como se ha podido comprobar a lo largo de este último apartado, el distrito Centro es la conjugación de seis barrios con elevadas disparidades entre ellos. De hecho, la división entre el norte y el sur que escinde a la ciudad de Madrid (Méndez y Prada- 
Trigo, 2014) vuelve a aparecer de nuevo sobre Centro, donde las diferencias socioeconómicas más dispares se dan entre el barrio más septentrional (Justicia) y el más meridional (Embajadores).

Por último, no debe dejar de tenerse en cuenta la demostrada influencia que provoca el alquiler turístico sobre los barrios, sobre todo en aquellos cuyas condiciones socioeconómicas son más bajas, como Sol y sobre todo Embajadores, porque los hacen más vulnerables de cara a la presión ejercida mediante el alquiler de corta duración. Pues más allá del rédito económico que se pueda extraer mediante esta actividad, no se puede descuidar la calidad de vida urbana de los residentes de la ciudad, así como su legítimo derecho a habitar.

\section{EL ALQUILER RESIDENCIAL EN DISTRITO CENTRO}

La ciudad, como centro de acumulación de recursos, capital humano y monetario resulta ser uno de los marcos más favorables para la expansión del mercado inmobiliario, el cual encuentra en la vivienda uno de sus principales acicates, a la vez que sirve de sustento para propietarios, inquilinos, especuladores y turistas.

La expansión inmobiliaria ha sido uno de los buques insignia del modelo de desarrollo español, el cual a su vez se apuntalaba sobre el mundo financiero mediante el endeudamiento y sobre la actividad turística como mecanismo de absorción de lo que resultó ser una sobreoferta inmobiliaria (Murray, 2015). En el ciclo desarrollista iniciado en 1995, durante el cual se fue inflando la burbuja que acabaría explotando en 2008, la vivienda se conformó como pieza central de la economía familiar gracias a la concesión de créditos hipotecarios por parte de los bancos, así como por el conjunto de políticas que se llevaron a cabo por parte del Estado como promotor, para encarrilar tal vacuo crecimiento (López y Rodríguez, 2010; López, 2007; Naredo, 2019).

Los antecedentes de la expansión urbana de Madrid se enraízan en la vasta promoción residencial realizada desde mediados del siglo XX, pues entre 1955 y 1975 proliferaron más de 10.000 hectáreas de suelo artificial en Madrid (Rodríguez, 2001). Desde entonces, la ciudad de Madrid no ha dejado de crecer, a menudo a través de pulsaciones urbanísticas aceleradas y caóticas, las cuales han dejado tras de sí un tejido urbano difuso, grandes áreas inconexas dedicadas al comercio y al ocio, así como sobredimensionadas infraestructuras de transporte (López, 2007: 171). El desarrollo económico de Madrid se ha sustentado sobre un conjunto de inversiones en capital fijo de largo plazo, es decir, sobre el circuito secundario. El cual necesita un mayor tiempo para la amortización que del que precisa el circuito primario, basado en la obtención de los beneficios a través de la producción de bienes y servicios (López, 2007: 171).

Partiendo desde la fase de despegue de la burbuja inmobiliaria entre 1998 y 2001, pasando por la fase central del proceso especulativo inmobiliario entre 2002 y 2006 y llegando a la caída de ella en 2008, se produjo una moderación de los precios de la vivienda (López y Rodríguez, 2010; López, 2007: 171). Sin embargo, el ciclo de caída de los precios de la vivienda no ha perdurado (Naredo, 2019), sino que ha ido remontando con el paso de los años, de forma que en el primer trimestre de 2018 los precios de venta de 
la vivienda de segunda mano en el distrito Centro de Madrid ya han sobrepasado el pico vivido durante la anterior burbuja al situarse en la actualidad en los $4.832 € / \mathrm{m}^{2}$, mientras que en el año 2007 se había llegado al cénit en los $4.728 € / \mathrm{m}^{2}$.

Siguiendo con el ejemplo del comportamiento del mercado inmobiliario del distrito Centro de Madrid, el siguiente gráfico muestra el precio de compra de la vivienda de segunda mano para cada uno de los barrios de Centro.

El mercado del alquiler residencial en Madrid siguió la estela marcada por el mercado de la vivienda de segunda mano -representado en la figura 3-, al estar ambos en estrecha correlación. El precio del alquiler llegó a su cénit en el año 2007 y comenzó su descenso hasta 2015, año de inflexión y momento inicial a la vuelta del encarecimiento de la vivienda.

\section{Figura 3 \\ GRÁFICO DEL PRECIO DE LA VIVIENDA DE SEGUNDA MANO EN EL DISTRITO CENTRO DE MADRID, SUS BARRIOS Y LA CIUDAD DE MADRID DURANTE LOS AÑOS 2007-2018}

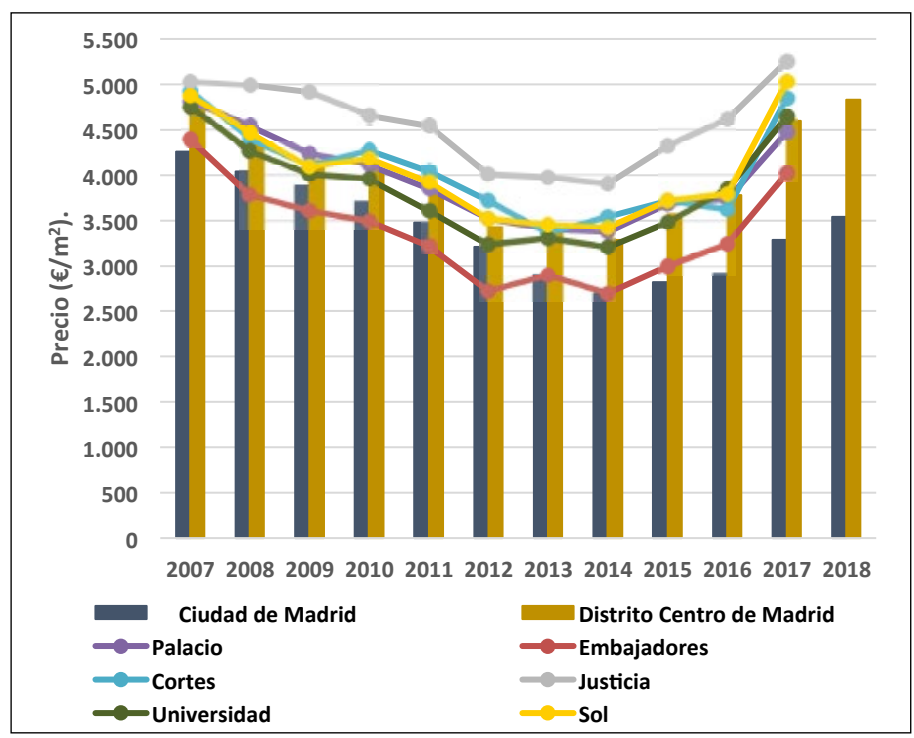

Fuente: Elaboración propia a partir de datos del Ayuntamiento de Madrid.

En la figura 4 se encuentra la evolución de los precios del alquiler residencial desde el año 2007 hasta el 2018 para aquellos distritos cuya media de alquiler durante estos años se encuentra por encima de los 13 euros $/ \mathrm{m}^{2}$, siendo los distritos con el alquiler de larga duración más caro del municipio de Madrid.

El metro cuadrado más caro de Madrid se encuentra en Centro, algo que no llama excesivamente la atención, pues ha sido su tendencia durante años. Sin embargo, cabe remarcar como ha repuntado el precio en este distrito desde 2015, con una subida notablemente pronunciada desde entonces hasta la actualidad. 
Frente a tal recalentamiento de precios, resulta difícil no recordar la pasada burbuja inmobiliaria vivida, solo que esta vez se ha seguido un camino distinto. Siguiendo a Naredo (2019), en la actualidad no existen grandes tasas de endeudamiento para fijar el capital en inmuebles, sino que los precios del alquiler se están calentado con unas energías distintas, como son las plataformas dedicadas al alquiler turístico y las corporaciones transnacionales que se dedican a la inversión extranjera masiva con fines especulativos. Así, no es difícil entender que en 2018 el arrendamiento en Centro sea un 8,12\% más elevado que el precio al que se llegó en pleno cenit de la burbuja anterior, de forma que no solo se ha llegado a ese techo, sino que se ha hecho añicos y se ha sobrepasado.

\section{Figura 4 \\ GRÁFICO SOBRE EL PRECIO DEL ALQUILER RESIDENCIAL EN CENTRO Y ALGUNOS DISTRITOS DE MADRID, DESDE 2007 HASTA 2018}

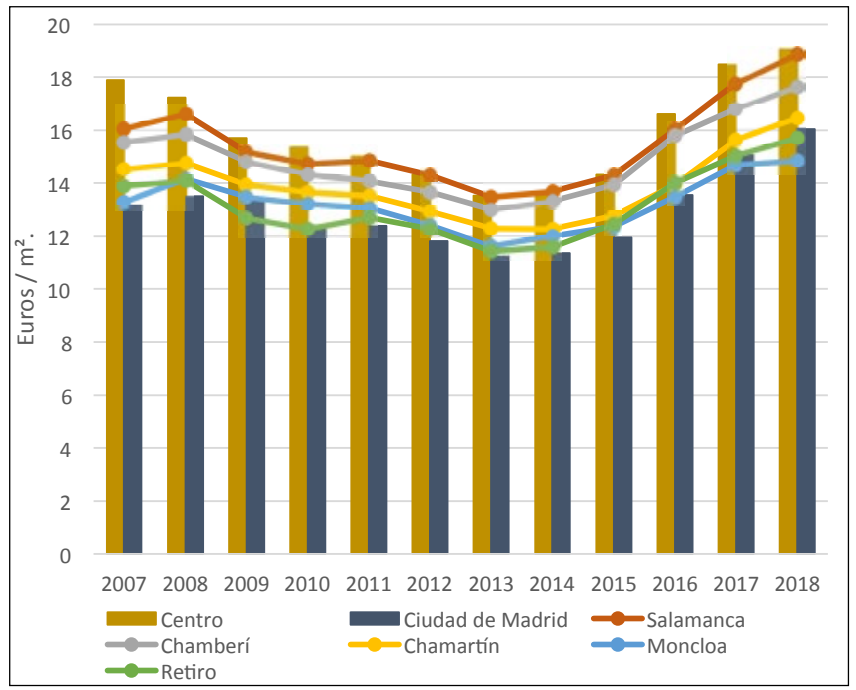

Fuente: elaboración propia a partir de datos de portales inmobiliarios y del Ayuntamiento de Madrid.

Por último, en la figura 5 se ha analizado brevemente el mercado de las habitaciones de alquiler de larga duración en Centro a partir de una muestra detallada de 300 ofertas; si bien para saber los volúmenes generales por barrio se tomaron el número total de habitaciones, dando 1.437 para Centro. De todo ello se ha extraído el número de habitaciones por hectárea; la media de personas por vivienda compartida; el arrendamiento medio por habitación y el precio medio por metro cuadrado. Sobre este mercado es en el barrio de Sol donde se da el mayor número de habitaciones por hectárea, llegando a las 8 , mientras que Palacio y Justicia son los barrios con la menor oferta de este tipo. La media de personas por vivienda compartida en Centro es de 5 personas, estando Universidad y Embajadores por debajo de ella; así como Sol y Justicia por encima. En cuanto a los arrendamientos de las habitaciones de larga duración, los más elevados se encuentran en Universidad y Jus- 
ticia, mientras que el más económico es Embajadores con 392 euros al mes. Sin embargo, y al observar el precio por metro cuadrado, es precisamente en Embajadores donde resulta más caro el alquiler de una habitación con $20,74 € / \mathrm{m}^{2}$, estando por encima del precio por metro cuadrado que alcanza la vivienda de alquiler residencial en el mismo barrio.

\section{Figura 5}

MAPA 1: HABITACIONES OFERTADAS POR HECTÁREA; MAPA 2: NÚMERO MEDIO DE PERSONAS POR VIVIENDA COMPARTIDA; MAPA 3: ARRENDAMIENTO MEDIO DE LAS HABITACIONES; MAPA 4: PRECIO MEDIO POR METRO CUADRADO

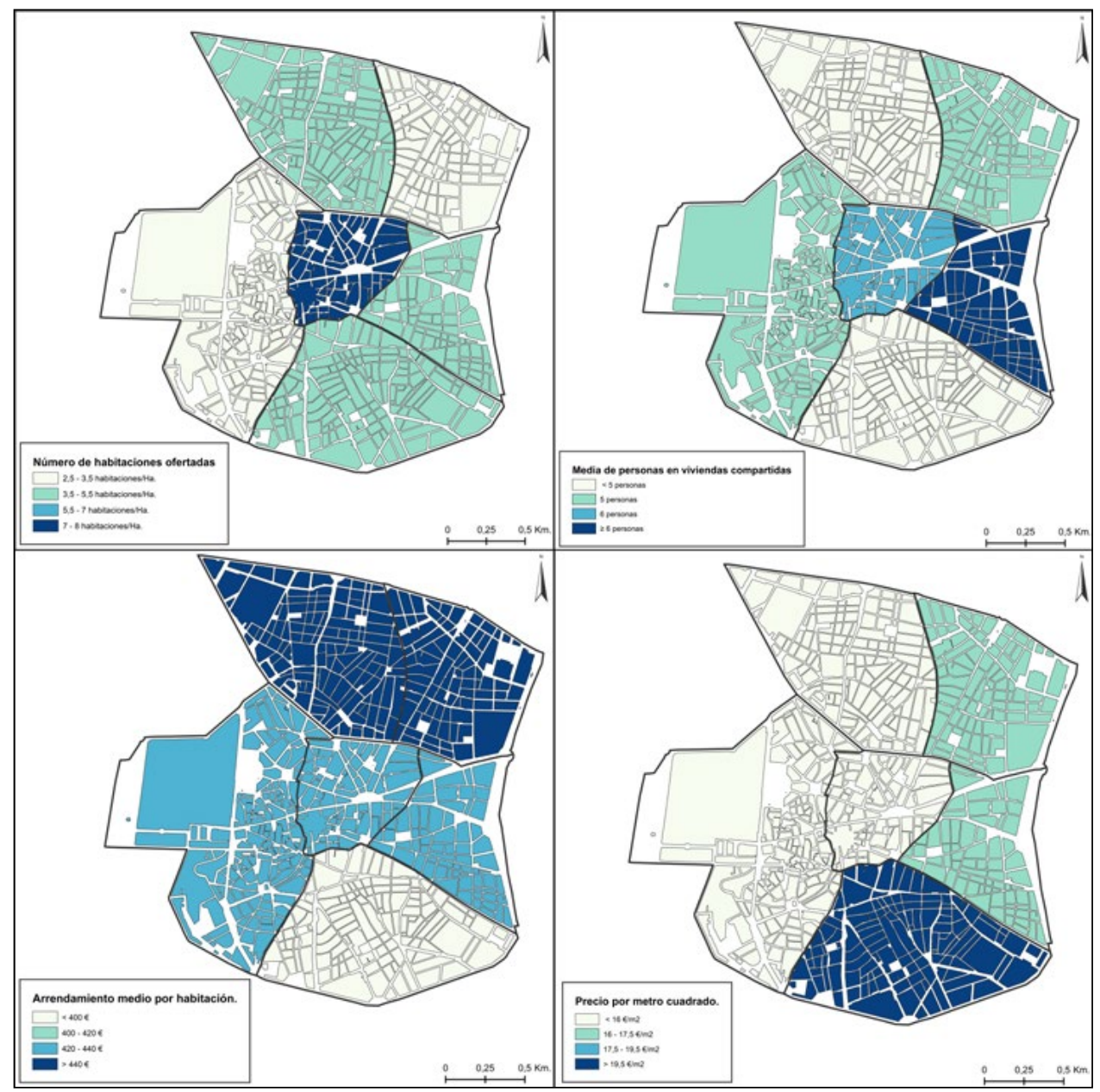

Fuente: Elaboración propia a partir de muestras extraídas por web scraping de portales inmobiliarios en el mes de junio de 2018 . 


\section{EL ALQUILER TURÍSTICO Y RESIDENCIAL EN LUCHA POR EL DIS- TRITO CENTRO}

Los habitantes, con el desarrollo de su cotidianidad engranan la ciudad y la construyen, al hacerla suya mediante sus actos y habitarla mediante el valor de uso. Pero a su vez, la ciudad también es lugar de explotación del valor de cambio a través del consumo de bienes y lugares (Lefebvre, 2017 [1968]; Morell, 2018). La explotación de la ciudad la secciona para su producción, siendo consumida tanto por los habitantes como por los visitantes.

En espacios específicos dedicados a una explotación turística intensa, se generan tensiones entre habitantes y turistas por el espacio, de forma que el foco del conflicto del turismo parece recaer en un principio sobre ellos y, sin embargo, son los grandes agentes turísticos los que mercadean a costa de ambos y explotan el territorio por la acumulación del capital.

En el caso de Centro, el éxito de Airbnb no se debe a la economía colaborativa, sino a la plusvalía que ha sido capaz de generar al abrir una brecha de rédito económico mediante la explotación de viviendas para fines turísticos. Pero ello contrae riesgos de gran calado, pues el alquiler turístico supone una competencia directa para el alquiler residencial, ya que, para su práctica más rentable, como es el alquiler de viviendas enteras, es necesario despojar a la vivienda de su valor de uso como hábitat.

El presente apartado se ha centrado en analizar la distribución espacial de las viviendas mediante la tipología de su uso, así como las consecuencias que tiene Airbnb sobre el mercado inmobiliario en distrito Centro y en la ciudad de Madrid. En primer lugar, se ha calculado el peso que tiene el alquiler turístico frente al total de viviendas dedicadas al alquiler residencial a nivel de sección censal; en segundo lugar, se ha calculado la brecha de renta para cada uno de los barrios de Centro y, en tercer lugar, se ha discernido la correlación existente entre los precios de Airbnb y los del mercado residencial en la ciudad de Madrid.

En base a las cifras de ofertas anunciadas mediante Airbnb en el mes de junio del año 2018 y al conjunto de las viviendas residenciales recogidas en el Catastro para el año 2017, se ha comprobado que los porcentajes de alojamientos explotados bajo Airbnb son los siguientes: $12,15 \%$ en Universidad; 12,97\% en Embajadores; 13,46\% en Justicia; 13,78\% en Palacio; $18,20 \%$ en Cortes y $37,34 \%$ en Sol. Si bien los valores que acoge Airbnb son bastante elevados en todos los barrios, la conversión de viviendas a esta tipología resulta sin duda flagrante en Sol.

Asimismo, también se ha medido el peso de Airbnb sobre el parque de viviendas destinadas a alquiler residencial recogidas en el último censo de 2011. Sin embargo, para este análisis cartográfico, no se han tenido en cuenta el total de ofertas de Airbnb, como en los porcentajes anteriores, sino que se han medido únicamente las viviendas enteras ofertadas en Airbnb sobre el total de viviendas de alquiler residencial contabilizadas en el Censo de 2011, es decir, tomando como el cien por cien el número de viviendas de alquiler residencial censadas. Ello puede servir de indicativo para observar los niveles de sustitución del alquiler de larga duración por alquiler turístico.

En este caso, la escala espacial es la sección censal, de manera que puede apreciarse con detalle en qué zonas de cada barrio se ha visto más afectado el alquiler residencial. Hay cuatro secciones censales donde el alquiler turístico representa más del 100\% sobre el alquiler residencial, es decir, que el número de viviendas enteras ofertadas como alquiler 
turístico ha sobrepasado al número de viviendas de alquiler residencial en estas secciones censales. De ello se extrae que en estas secciones censales se ha producido una conversión de usos, perdiendo viviendas de alquiler de larga duración en favor del alquiler turístico. La figura 6 muestra que la mayor concentración de la actividad de Airbnb se da en el flanco oriental del barrio de Sol, siendo de hecho el barrio de Centro donde con bastante probabilidad se han perdido más viviendas de alquiler de larga duración. De hecho, la sección censal con una menor conversión de Sol se encuentra en un 39\% de alojamiento vacacional sobre el residencial; mientras que las secciones censales con los valores más elevados alcanzan un $103 \%$, un $116 \%$ y un $128 \%$.

\section{Figura 6}

MAPA SOBRE EL PESO DE LAS VIVIENDAS ENTERAS DE ALQUILER VACACIONAL SOBRE EL CONJUNTO DE VIVIENDAS DE ALQUILER RESIDENCIAL A NIVEL DE SECCIÓN CENSAL EN CENTRO.

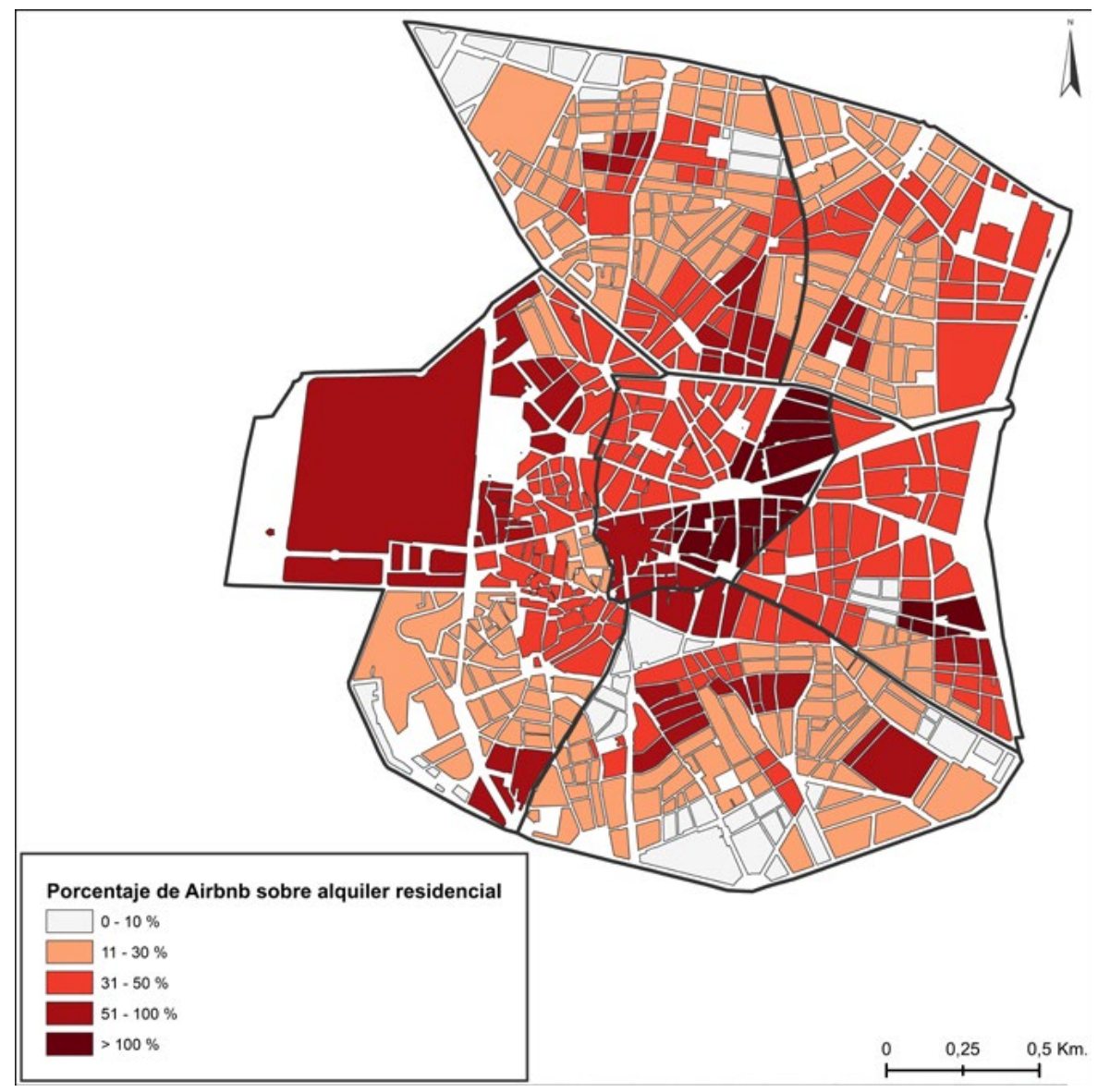

Fuente: Elaboración propia a partir del Censo de 2011 y de DataHippo. 
Asimismo, también desatacan las secciones censales más occidentales de Palacio; las septentrionales y centrales de Embajadores, así como las situadas al sur en Cortes, Justicia y Universidad. El alojamiento vacacional se ha abierto paso así en cada una de las secciones censales de Centro, lo que favorece la turistización del distrito mediante la reconversión de la vivienda, y por ende, a Airbnb.

¿Por qué una vivienda que opera bajo el alquiler de larga duración transmuta su uso hacia el alquiler turístico? La respuesta a esta pregunta ha sido el éxito de las plataformas como Airbnb; pues ellas han sido capaces de abrir una brecha de renta entre los alquileres de larga y corta duración, haciendo que los arrendadores consigan un mayor rédito económico sin la necesidad de recurrir a la reurbanización (Wachsmuth y Weisler, 2018).

La hipótesis de la diferencia potencial de la renta establece que tal brecha se fundamenta en la disparidad entre el nivel de renta potencial del suelo y la renta actual capitalizada en el uso de ese mismo suelo (Smith, 2012 [1996]). Junto a ello, se intercala el proceso de gentrificación, cuya fase inicial se encuentra cuando la valorización económica de un espacio urbano es tan baja, que los promotores inmobiliarios pueden comprar a precio de saldo y así reurbanizarlo con el objetivo de vender su producto por un alto precio a las capas de la sociedad que puedan permitírselo (Smith, 2012 [1996]). Con ello, el suelo se recapitaliza e inicia la explotación de su valor de uso bajo unas nuevas circunstancias.

Si bien el resultado feliz de Airbnb se ancla en la brecha de renta anunciada por Smith, su forma de desarrollo no sigue los pasos del hundimiento del suelo, aderezamiento y elevamiento de los precios bajo la recapitalización del suelo, sino que alza los precios del inmueble tan solo cambiando la forma de comercialización de este (Wachsmuth y Weisler, 2018). Igualmente, cabe decir que cualquiera puede incluir su vivienda en una plataforma como Airbnb, pero para que el alquiler turístico sea rentable debe encontrarse localizado en una zona que posea atractivos turísticos que explotar, así como una fuerte demanda turística que no sea local (Wachsmuth y Weisler, 2018). Allí radica el éxito del alquiler turístico en el distrito Centro de Madrid y sus alrededores más próximos, pues la distancia y un difícil acceso a los nichos de explotación turística son las verdaderas circunstancias capaces de estrangular al mercado del alquiler turístico.

La brecha de renta generada por el alquiler turístico en el distrito Centro se ha calculado en base a los dos indicadores empíricos utilizados para medir la intensidad de la disparidad entre los precios del alquiler de larga y corta duración en un estudio sobre la ciudad de Nueva York (Wachsmuth y Weisler, 2018). Tales indicadores son: 1) la media de los arrendamientos residenciales, y 2) la renta media ganada por los anfitriones de los listados de viviendas enteras alquiladas en Airbnb.

Las brechas de renta se han calculado a nivel de barrio porque no existe información actual de los arrendamientos de larga duración a nivel de sección censal. Así, se ha obtenido un resultado por cada uno de los seis barrios que conforman el distrito Centro de Madrid.

Como se puede observar en el cuadro 2, las brechas de renta de los barrios de distrito Centro se presentan muy abiertas, puesto que se encuentran muy cercanas a 1 . La brecha de renta abierta hace que el rendimiento económico del alquiler turístico sea mayor que el del alquiler residencial (Wachsmuth i Weisler, 2018), de forma que hay una rentabilidad potencial entre ambos alquileres distinta, siendo más elevada cuanto más cercana a 1 se encuentre. 
De ello se puede afirmar, que el decrecimiento natural de la oferta del alojamiento turístico en el casco histórico no se producirá por sí solo, pues la plusvalía es muy superior a la alcanzada mediante el alquiler de larga duración o residencial.

\section{Cuadro 2}

\section{TABLA CON LAS BRECHAS DE RENTA DE LOS BARRIOS DE DISTRITO} CENTRO

\begin{tabular}{|c|c|c|c|c|c|c|}
\hline $\begin{array}{c}\text { Barrios de Distrito } \\
\text { Centro }\end{array}$ & Universidad & Sol & Embajadores & Palacio & Cortes & Justicia \\
\hline Brecha de renta & 0,7013 & 0,7013 & 0,6923 & 0,6901 & 0,6871 & 0,6365 \\
\hline
\end{tabular}

$\mathrm{Al}$ observar las mensualidades generadas por ambos alquileres para los mismos barrios, tomando como el 100\% las ganancias del alquiler de larga duración, se obtiene que, bajo la presente brecha de renta, si se explota una vivienda bajo el alquiler turístico se ganará un $134,81 \%$ más que una vivienda de alquiler residencial en el caso del barrio de Universidad; un $134,73 \%$ en el barrio de Sol; un 125,04\% en Embajadores; un 122,72\% en Palacio; un $119,56 \%$ en Cortes y un $75,07 \%$ en Justicia.

Dicha situación, sin la regulación del mercado de la vivienda por parte de la administración, conlleva a la irremediable pérdida de alquileres residenciales en favor de turísticos, pues unas brechas de renta tan elevadas hacen que las ganancias de los primeros sobre los segundos resulten un atractivo económico difícil de eludir (Wachsmuth y Weisler, 2018; Horn y Merante, 2017; Yrigoy, 2019).

\subsection{Incidencia de la oferta de VUT en el mercado inmobiliario de Madrid}

El trasvase de alquiler de larga duración hacia el mercado del alquiler turístico implica una subida de precios para el primero. Pues tal como demuestran varios estudios sobre el mercado del alquiler, tal trasvase da como resultado que haya un menor número de viviendas disponibles para alquiler residencial mientras que la demanda para vivir en la ciudad mediante arrendamiento permanece, haciendo que el precio suba (Horn y Merante, 2017; Barron et al., 2018).

Si bien la pérdida de ofertas de alquiler residencial en Centro está facilitando la subida de los arrendamientos, también se piensa que el precio que se impone a través del alquiler turístico está influyendo en el precio del alquiler residencial. Con el objetivo de comprobar si existe una influencia estadísticamente significativa entre los precios del mercado inmobiliario turístico y residencial de Madrid; se ha llevado a cabo un estudio de correlación $r$ de Pearson. Las variables estudiadas mediante la correlación $r$ de Pearson, han sido: el precio medio por metro cuadrado del alquiler residencial, el precio medio por metro cuadrado de la vivienda de segunda mano y el precio medio por noche del alquiler turístico ofertado en Airbnb. Los valores para estas variables se han tomado para la ciudad de Madrid, así como para cada uno de los 21 distritos que la conforman, de forma que 
se han tenido 22 muestras para cada una de las variables. Asimismo, el periodo temporal estudiado para estas tres variables han sido los años 2015, 2016, 2017 y 2018.

Los resultados obtenidos, adjuntos en el cuadro 3, muestran como efectivamente existe una correlación positiva y elevada entre el precio del alquiler residencial, el de la vivienda de segunda mano y el precio del alquiler turístico. Entre el precio del alquiler turístico de 2018 y el precio del alquiler residencial para el mismo año se obtiene una $r$ de 0,819 , lo que demuestra al ser positiva y estar cercana a 1 , que cuanto más elevado sea el precio ofertado en Airbnb para los alquileres turísticos, más subirá también el precio del arrendamiento residencial.

\section{Figura 7}

\section{GRÁFICA DE RELACIÓN BIVARIADA ENTRE EL ALQUILER RESIDENCIAL Y VACACIONAL}

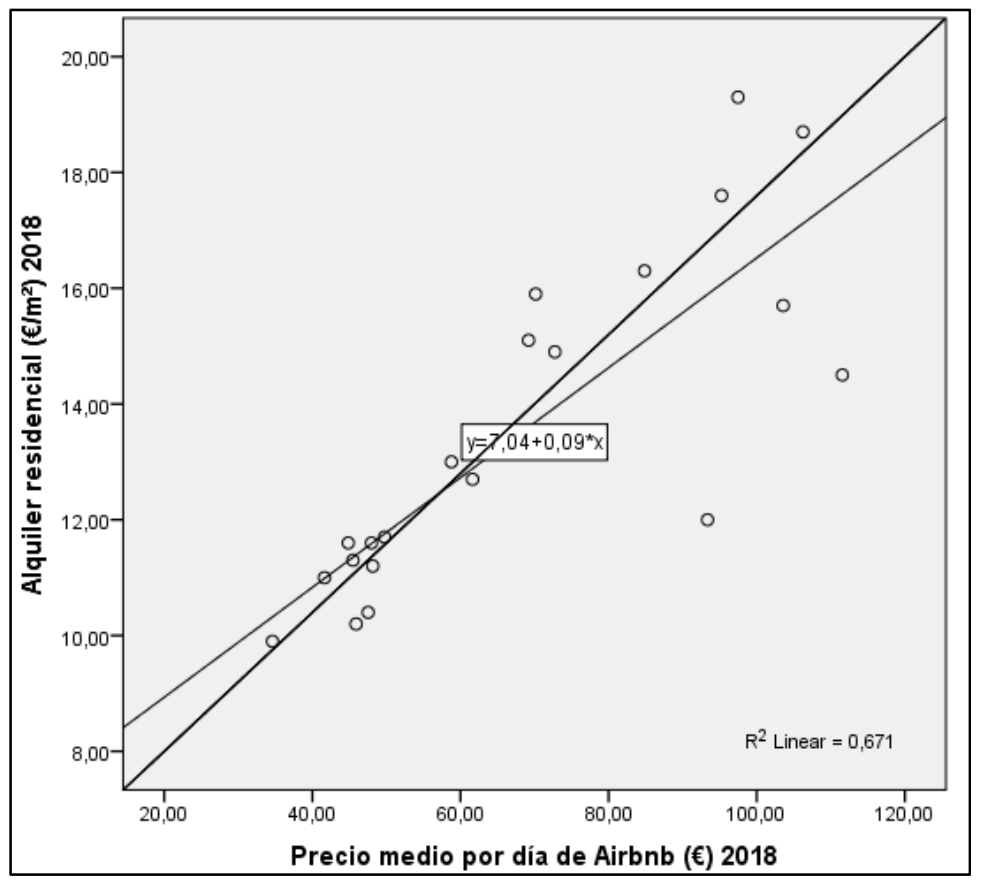

Fuente: elaboración propia a partir de InsideAirbnb y el Ayuntamiento de Madrid.

La séptima figura representa la gráfica de correlación bivariada mostrando la nube de puntos que acogen los valores del alquiler de corta y larga duración. De ella se extrae que tal nube de puntos responde a una relación rectilínea y correlacionada entre ambas variables. En este caso, la relación se mide por la correlación múltiple al cuadrado, la cual asciende a 0,67 , demostrando de nuevo la relación de condicionamiento que existe entre las dos variables estudiadas. 


\section{Cuadro 3}

\section{RESULTADOS DE LA CORRELACIÓN R DE PEARSON}

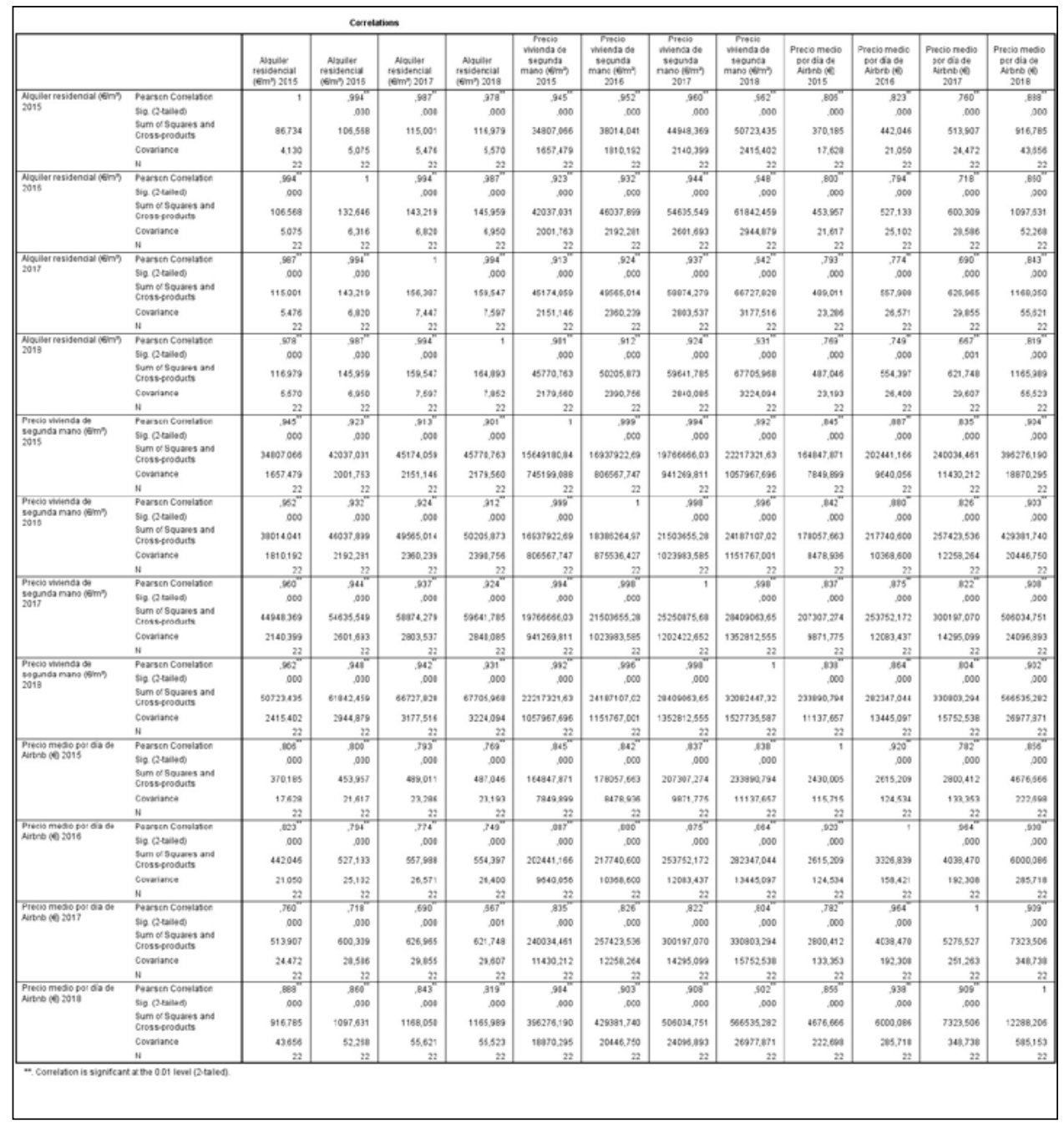

Fuente: Elaboración propia a partir del Ayuntamiento de Madrid y de InsideAirbnb.

Continuando con el cuadro adjunto sobre la correlación $r$ de Pearson, se ha observado que entre el precio de venta de la vivienda de segunda mano en 2018 y el precio del alquiler de larga duración, el valor de $r$ asciende hasta el 0,931, de forma que la correlación entre el precio de venta de las viviendas y los arrendamientos está estrechamente relacionada, pues cuando el precio de venta sube, el alquiler también lo hace. Por otro lado, la correlación entre el precio de la vivienda de segunda mano y el del 
alquiler ofertado en Airbnb se mantiene sobre una $r$ de 0,902 , de manera que sigue el mismo tipo de relación que las demás variables.

Atendiendo a los resultados obtenidos a lo largo del apartado, no es difícil entender que el paso final en la expansión del alquiler turístico se encuentre en la expulsión de los residentes que viven en la ciudad a través del alquiler de larga duración, siendo los que tienen un poder adquisitivo más bajo, los primeros en caer bajo la Airbnbificación (Richards, 2016). El turismo acelera la gentrificación, pues con él se desarrolla la práctica del alquiler turístico, el cual se cuece a través de la especulación inmobiliaria, de la subida de los precios del alquiler de larga duración y de la carencia de vivienda social (Cócola, 2016). Igualmente, también se apunta que el turismo fagocita la gentrificación mediante la acumulación por desposesión, pues a través del desequilibrado acopio de suelo urbano junto con sus consiguientes rentas, se favorece el desplazamiento de los desposeídos (González-Pérez, 2019; Vives-Miró y Rullan, 2017). Además, en la gestión de la crisis se han potenciado los mecanismos de financiarización de la vivienda, que en el caso de Madrid se han visto plasmados en la penetración del fondo de inversión Blackstone, convertido en el mayor propietario de viviendas después de la privatización del parque público. Ello ha aumentado las tensiones sobre la vivienda y se ha reflejado en los precios del alquiler. No obstante, su presencia es sobre todo significativa en los barrios del sur de Madrid (Janoschka et al., 2020). Así pues, podemos subrayar dos dinámicas del capital complementarias que sacuden a las clases populares y las despojan de la vivienda: fondos de inversión en el Sur y Airbnb en el centro.

\section{CONCLUSIONES}

El alquiler turístico auspiciado por plataformas como Airbnb, ha resultado una sobreexplotación de la vivienda, mediante la cual el turismo está conquistando ciudades del Norte Global. El casco histórico de Madrid es ejemplo de ello, pues el distrito Centro se está convirtiendo en un auténtico resort turístico, al concentrar el mayor número de ofertas de Airbnb.

Las consecuencias derivadas de la explotación del alquiler turístico se han ido materializando en cada uno de sus barrios. Así, la gravedad de los perjuicios, como por ejemplo la presión sobre los inquilinos para que dejen sus viviendas o el alboroto en los barrios a altas horas de la noche, está acompasada con la intensidad con la que penetra Airbnb. Los efectos del alquiler turístico no son socioespacialmente inocuos, sino que tienen unas consecuencias tangibles y reales, en forma de gentrificación, turistificación, expulsión de población residente y, en definitiva, de pérdida de habitabilidad en los barrios. La vida en los barrios va cambiando, se va vaciando, recordando aquella metáfora que utilizaba Jane Jacobs sobre el zumbido de la ciudad. Son las personas que viven en la ciudad las que la llenan de sentido y significado y cuando la ciudad se vacía, por mercantilización turística en este caso, la ciudad muere.

Dentro de los límites del casco histórico son Sol y Embajadores, los barrios que sufren la mayor presión mediante ofertas de Airbnb, y que por tanto, podemos concluir que estos son los barrios más turistizados de la ciudad. Además, la concentración de las viviendas 
Airbnb en estos barrios se da debido a su centralidad turística, al encontrarse en ellos los principales puntos de atracción turística.

Sin embargo, no toda la problemática subyace sobre Airbnb, sino que ésta se encuentra modulada a su vez por otro tipo de factores, como es el nivel socioeconómico del barrio en cuestión. La intensidad del alquiler turístico se debe relacionar con el nivel socioeconómico, pues cuanto más bajo sea este, más vulnerable serán sus residentes. Es decir, los barrios de las clases populares resultan ser aquellos en los que la Airbnbificación aumenta su vulnerabilidad. De esta forma, Embajadores se convierte en el barrio más vulnerable, pues en él se conjugan ambos aspectos de manera prominente, con el nivel socioeconómico más bajo y una elevadísima explotación de viviendas mediante alquiler turístico. La vulnerabilidad socioeconómica de Embajadores hace que se produzca en mayor medida el fenómeno descrito como gentrificación por Airbnbificación. De forma que se pone en riesgo directo a los arrendatarios de larga duración de este barrio debido a la conjugación del encarecimiento de los alquileres y a sus limitaciones para poder hacerles frente, acarreando como consecuencia las expulsiones de población residente.

La inactividad por parte de la administración pública para contener la vorágine especulativa inmobiliaria desata virulentas consecuencias, tanto para la ciudad -al hacerla menos habitable- como para los residentes, al ser expulsados del lugar. Si bien la catastrófica situación que se vive en la actualidad es un complejo entramado, pueden distinguirse las principales variables que lo conforman.

En primer lugar, se encuentra el solapamiento entre el alquiler turístico y el alquiler residencial. Mediante la cartografía se ha mostrado la confrontación espacial entre ambos alquileres, la cual ha viralizado la transformación de viviendas en "hoteles" encubiertos. Al subyugar la vivienda bajo la mercantilización turística, se produce un impacto de gran calado sobre el tejido urbano, pues si bien el turismo ya tenía el "usufructo" de partes de la ciudad mediante las denominadas atracciones turísticas, con la expugnación de las viviendas se ha pasado a dominar lo que serían las propias células del cuerpo urbano. Lo que conlleva a la alienación espacial mediante el cambio de funcionalidad de los barrios, sin olvidar las pérdidas de población permanente por población pasajera.

En segundo lugar, se encuentra la brecha de renta ensanchada por Airbnb en la ciudad de Madrid. La vehemencia con la que muchos de los propietarios actúan al explotar sus bienes inmuebles bajo estas condiciones, se explica gracias a la brecha de renta, la cual como se ha observado, se encuentra muy abierta en Centro, haciendo que las ganancias del alquiler turístico sean mucho más elevadas, que las percibidas mediante el alquiler de larga duración. Lo que conduce a su vez, a que se produzca el trasvase de viviendas destinadas a arrendamientos de larga duración, hacia el alquiler turístico.

En tercer lugar, cabe tener en cuenta la estrecha correlación entre los precios del alquiler turístico, residencial y de compraventa de viviendas. Pues tal y como se ha demostrado, existe una conexión real entre las distintas mercantilizaciones de los inmuebles que hemos demostrado estadísticamente. Lo cual permite que durante el calentamiento de precios que se está viviendo en la actualidad, se homogeneice y se contagie el encarecimiento entre un tipo de comercialización inmobiliaria y las otras.

Sobre la balanza, se encuentran los mismos protagonistas de siempre, los amos del capital por un lado y los desposeídos, por el otro. El poder político debe elegir una vez más 
a quien favorecer, así como qué tipo de ciudad se quiere para el futuro. En la actualidad, las ciudades son meras vías de rentabilidad económica, manejadas como empresas, por la acumulación del capital. Pero no tienen por qué serlo, pues pueden llegar a convertirse en espacios capaces de acoger a todo el que quiera habitarlo. Pues, al fin y al cabo, la voluntad de los que necesitan habitar es inmarcesible, y una ciudad sin habitantes, es tierra baldía. Precisamente, los movimientos urbanos de resistencia a la Airbnbificación nos indican que "otras ciudades son posibles".

Finalmente, y a pesar de los extensos estudios realizados acerca de este fenómeno, solo se ha llegado a vislumbrar parte del camino por el cual se está abriendo paso Airbnb, sirviendo de ejemplo el presente artículo. De forma que se descubre un extenso abanico para la continuación de esta vía de investigación, pues son muchas las preguntas que aún quedan por responder.

\section{BIBLIOGRAFÍA}

AYUNTAMIENTO DE MADRID. Banco de datos. [En línea]. http://www- 2.munimadrid. es/CSE6/control/menuCSE?filtro=NS\&tablaSerie=SERIES [Consulta 01/08/2018].

BARRON, K., KUNG, E. y PROSERPIO, D. (2018): «The Sharing Economy and Housing Affordability: Evidence from Airbnb», SSRN, pp. 1-62.

BENÍTEZ-AURIOLES, B. (2017): «The role of distance in the peer-to-peer market for tourist accommodation», Tourism Economics, vol. 24 (3), pp. 237-250.

BLANCO-ROMERO, A., BLÁZQUEZ-SALOM, M. y CÀNOVES, G. (2018): «Barcelona, housing rent bubble in a tourist city. Social responses and local policies», Sustainability, vol. 10 (6), pp. 1-18.

BOSQUE, J. y MORENO, A. (1994): Prácticas de análisis exploratorio y multivariante de datos. Barcelona, Oikos-tau.

BRUNET, I., PASTOR, I. y BELZUNEGUI, A. (2002): Tècniques d'investigació social. Fonaments epistemològics i metodològics. Barcelona, Pòrtic.

CAMACHO, J. (2005): Estadística con SPSS para Windows versión 12. Madrid, RA-MA Editorial.

CAÑADA, E. y MURRAY, I. (2019): Turistificación global. Perspectivas críticas en turismo. Barcelona, Icaria Editorial.

COCKAYNE, D. G. (2016): «Sharing and neoliberal discourse: The economic function of sharing in the digital on-demand economy», Geoforum, vol. 77, pp. 73-82.

CÓCOLA, A. (2016): «Alojamiento turístico y desplazamiento de población», Contested cities, $\mathrm{n}^{\circ} 3$, pp. 1-13.

CROMMELIN, L., TROY, L., MARTIN, C. y PETTIT, C. (2018): «Is Airbnb a Sharing Economy Superstar? Evidence from Five Global Cities», Urban Policy and Research, vol. 36 (4), pp. 429-444.

GARCÍA-AYLLON, S. (2018): «Urban Transformations as an Indicator of Unsustainability in the P2P Mass Tourism Phenomenon: The Airbnb Case in Spain through Three Case Studies», Sustainability, vol. 10, pp. 1-21. 
GIL, J. (2017): «Desigualdades, límites y posibilidades para la transformación del capital en las economías colaborativas», Revista de Estudios para el Desarrollo Social de la Comunicación, $\mathrm{n}^{\circ} .15$, pp. 32-67.

GIL, J. y SEQUERA, J. (2018): «Expansión de la ciudad turística y nuevas resistencias. El caso de Airbnb en Madrid», EMPIRIA. Revista de Metodología de Ciencias Sociales, $\mathrm{n}^{\circ}$ 41, pp. 15-32.

GONZÁLEZ-PÉREZ, J.M. (2019): «The dispute over tourist cities. Tourism gentrification in the historic Centre of Palma (Majorca, Spain)», Tourism Geographies, pp.1-21.

HARVEY, D. (2014): Diecisiete contradicciones del capital y el fin del capitalismo. Madrid, Traficantes de Sueños.

HERNÁNDEZ AJA, A., MATESANZ PARELLADA, A., GARCÍA MADRUGA, C., ALGUACIL GÓMEZ, J., CAMACHO GUTIÉRREZ, J. y FERNÁNDEZ RAMÍREZ, C. (2015): Atlas de Barrios Vulnerables de España: 12 Ciudades 1991/2001/ 2006. Madrid, Instituto Juan de Herrera.

HORN, K. y MERANTE, M. (2017): «Is home sharing driving up rents? Evidence from Airbnb in Boston», Journal of Housing Economics, vol. 38, pp. 14-24.

INSTITUTO NACIONAL DE ESTADÍSTICA. (2015): Indicadores Urban Audit para áreas submunicipales, [En línea]. https://www.ine.es/jaxiT3/Tabla.htm?t=24173 [Consulta $01 / 08 / 2018]$.

INSTITUTO NACIONAL DE ESTADÍSTICA. (2017): Indicadores Urban Audit para áreas submunicipales, [En línea]. http://www.ine.es/jaxiT3/Tabla.htm?t=28234 [Consulta 01/08/2018].

JANOSCHKA, M., ALEXANDRI, G., OROZCO RAMOS, H. y VIVES-MIRÓ, S. (2020): «Tracing the socio-spatial logics of transnational landlords' real estate investment: Blackstone in Madrid», European Urban and Regional Studies, vol. 27 (2), pp. 125-141.

LEFEBVRE, H. (2017) [1968]: El derecho a la ciudad. Madrid, Capitán Swing.

LÓPEZ, I. (2007): «Sin los pies en el suelo. Acumulación de capital y ocupación de territorio en la Comunidad de Madrid», en Observatorio Metropolitano. Madrid: ¿la suma de todos? Globalización, territorio, desigualdad. Madrid, Traficantes de Sueños, pp. 171-214.

LÓPEZ, I. y RODRÍGUEZ E. (2010): Fin de ciclo. Financiarización, territorio y sociedad de propietarios en la onda larga del capitalismo hispano (1959-2010). Madrid, Traficantes de sueños.

MARTÍNEZ-CALDENTEY, M.A. y MURRAY, I. (2019): «Crisis y desarrollo geográfico desigual en la Unión Europea (2009-2015)», Revista de Geografía Norte Grande, Vol. 72, pp. 1-22.

MILANO, C. y MANSILLA, J.A. (2018): Ciudad de vacaciones. Conflictos urbanos en espacios turísticos. Barcelona, Pol·len.

MÍNGUEZ, C., PIÑEIRA, M.J. y FERNÁNDEZ-TABALES, A. (2019): «Social vulnerability and touristification of historic centers», Sustainability, Vol. 11, 4478, pp. 1-24.

MÉNDEZ, R. y PRADA-TRIGO, J. (2014): «Crisis, desempleo y vulnerabilidad en Madrid», Scripta Nova. Revista Electrónica de Geografía y Ciencias Sociales, Vol. XVIII, Núm. 474, pp. 1-22. 
MORELL, M. (2018): «Urban tourism via dispossession of ouvre, Labour as a common denominator», Focaal 8(82), pp. 35-48.

MURRAY, I. (2015): Capitalismo y turismo en España. Del "milagro económico" a la "gran crisis". Barcelona, Alba Sud.

NAREDO, J.M. (2019): «Diagnóstico del panorama inmobiliario actual. ¿Rebrota una burbuja inmobiliaria comparable a la anterior?», Papeles de Relaciones Ecosociales y Cambio Global, $\mathrm{n}^{\circ} 145$, pp. 129-140.

RICHARDS, G. (2016): «El turismo y la ciudad: ¿hacia nuevos modelos?», Revista CIDOB d'Afers Internacionals, $\mathrm{n}^{\circ}$. 113, pp. 71-87.

RIVERA, J., GORDO, A. y CASSIDY, P. (2017): «La economía colaborativa en la era del capitalismo digital», Revista de Estudios para el Desarrollo Social de la Comunicación, $\mathrm{N}^{\mathrm{o}}$. 15 , pp. 20-31.

RODRÍGUEZ, I. (2001): Vivienda y promoción inmobiliaria en Madrid. Lleida, Universitat de Lleida.

ROGERSON, P. (2015): Statistical methods for geography. A student's guide. London, SAGE.

SILVER, D. y NICHOLS, T. (2013): «Buzz as an Urban Resource”, Canadian Journal of Sociology», Vol. 38 (1), pp. 1-32.

SMITH, N. (2012) [1996]: La nueva frontera urbana. Ciudad revanchista y gentrificación. Madrid, Traficantes de sueños.

VIVES-MIRÓ, S. y RULLAN, O. (2017): «¿Desposesión de vivienda por turistización? Revalorización y desplazamientos en el Centro Histórico de Palma (Mallorca)», Revista de Geografía Norte Grande, Vol. 67, pp. 53-71.

WACHSMUTH, D. y WEISLER, A. (2018): «Airbnb and the Rent Gap: Gentrification Through the Sharing Economy», Environment and Planning A: Economy and Space, Vol. 50 (6), pp. 1.147-1.170.

YRIGOY, I. (2017): «Airbnb en Menorca: ¿una nueva forma de gentrificación turística?: Localización de la vivienda turística, agentes e impactos sobre el alquiler residencial», Scripta Nova. Revista Electrónica de Geografía y Ciencias Sociales, Vol. XXI, N. 580, pp. 1-31.

YRIGOY, I. (2019): «Rent gap reloaded: Airbnb and the shift from residential to touristic rental housing in the Palma Old Quarter in Mallorca, Spain», Urban Studies, vol. 46 (13), pp. 2.709-2.726. 
